\title{
A EXPANSÃO URBANA DA CIDADE DE ARARANGUÁ, SANTA CATARINA, NO PERÍODO DE 1957 A 2010 E SUAS IMPLICAÇÕES AMBIENTAIS
}

THE URBAN GROWTH AND SPRAWL OF ARARANGUÁ CITY, SANTA CATARINA STATE, FROM 1957 TO 2010 AND THE ENVIRONMENTAL CONSEQUENCES

\section{Luciléia Marcon}

Mestre em Ciências Ambientais pelo Programa de Pós-Graduação em Ciências Ambientais (PPGCA), Universidade do Extremo Sul Catarinense (UNESC). Docente do Instituto Federal de Educação, Ciência e Tecnologia de Santa Catarina (IFSC) - Criciúma (SC), Brasil.

\section{Jairo José Zocche}

Doutor em Ciências pela Universidade Federal do Rio Grande do Sul (UFRGS). Docente pesquisador do Programa de PósGraduação em Ciências Ambientais, UNESC. Coordenador do Laboratório de Ecologia de Paisagem e de Vertebrados (LABECO), UNESCCriciúma (SC), Brasil.

\section{Nilzo Ivo Ladwig}

Doutor em Engenharia Civil pela Universidade Federal de Santa Catarina (UFSC). Docente pesquisador do Programa de Pós-Graduação em Ciências Ambientais, UNESC. Coordenador do Laboratório de Planejamento e Gestão Territorial (LPGT), UNESCCriciúma (SC), Brasil.

\section{Endereço para correspondência:}

Jairo José Zocche - Universidade do Extremo Sul Catarinense (UNESC) Avenida Universitária, 1.105 - Bairro Universitário-88806-000-Bloco S (Sala 24) - Criciúma (SC), Brasil E-mail: lucileia.marcon@ifsc.edu.br

Recebido: 02/08/2015

Aceito: 06/03/2017

\section{RESUMO}

Este estudo teve por objetivo mapear a expansão urbana da cidade de Araranguá, Santa Catarina, no período de 1957 a 2010, e analisar as implicações ambientais sobre locais com cotas altimétricas baixas, áreas úmidas, entorno de nascentes e corpos d'água. O mapeamento e a elaboração de mapas temáticos se deram por meio de técnicas de geoprocessamento. Foi adotado o perímetro ocupado pela malha urbana, em 2010, como a área para análise multitemporal das mudanças ocorridas nas formas de uso e cobertura da terra. Sobre esse perímetro foi acrescido um buffer de $2 \mathrm{~km}$ de raio para a verificação dos espaços propícios à expansão urbana. $O$ rápido avanço da malha urbana de Araranguá sobre as áreas de preservação permanente (APPs), assim como a degradação ambiental verificada, nos alerta para a urgência de uma revisão do Plano Diretor Municipal, bem como o estabelecimento de programas de gestão territorial que tenham por base a interdisciplinaridade.

Palavras-chave: crescimento urbano; paisagem; geoprocessamento.

\section{ABSTRACT}

This study aims to map the urban sprawl in the city of Araranguá, Santa Catarina, and to analyze the environmental implications on water springs, wetlands and water bodies. The mapping and elaboration of thematic maps were done through geoprocessing techniques. The perimeter occupied by the urban mesh in $\mathbf{2 0 1 0}$ was adopted as the area to be mapped for the multitemporal analysis of land use and cover changes. Above this perimeter was added a buffer of two kilometers radius for the verification of the spaces proper to the future urban sprawl. The rapid advance of the urban area of Araranguá city above the Permanent Preservation Areas, as well as the environmental degradation verified, alerts us to the urgency in the revision of the Municipal Master Plan, as well as the establishment of territorial management programs based on interdisciplinarity.

Keywords: urban sprawl; landscape; geoprocessing. 


\section{INTRODUÇÃO}

A urbanização é uma tendência demográfica dominante e um componente importante da transformação global da Terra (WU et al., 2013). Crescimento e expansão urbana, embora sejam fenômenos que têm a mesma origem (o crescimento populacional humano), não são sinônimos, mas sim faces opostas da mesma moeda; portanto, é importante distingui-los e compreendê-los.

De acordo com Bhatta (2010), as causas do crescimento e da expansão urbana são muito semelhantes e, na maior parte dos casos, não podem ser distinguidas, uma vez que ambos os processos estão altamente interligados. $\mathrm{O}$ autor assinala que o crescimento urbano pode ser observado sem a ocorrência de expansão, mas o contrário não acontece, pois a expansão urbana leva ao crescimento da área urbana. 0 crescimento populacional pode resultar em crescimento compacto e coordenado (crescimento vertical) ou em crescimento alargado (expansão urbana), o qual pode se dar tanto de forma ordenada quanto desordenada.

As ciências naturais e sociais enfrentam na atualidade um grande desafio: compreender o papel dos humanos nos ecossistemas, especialmente nos ecossistemas urbanos (ALBERTI, 2008). A estrutura complexa assumida pelas cidades em todo o mundo resultou em padrões complexos de uso dos recursos naturais da Terra (ALSHARIF \& PRADHAN, 2014). Diversos estudos têm sido realizados sobre a expansão urbana (ALBERTI, 2008; AL-SHALABI et al., 2012; 2013; ALSHARIF \& PRADHAN, 2014; ALSHARIF et al., 2015; ABUTALEB \& AHMED, 2016; GROFFMAN et al., 2016; PRAMANIK \& STATHAKIS, 2016; STEWARD et al., 2017), mas as interações entre os processos humanos e a dinâmica dos ecossistemas e suas consequências sobre os sistemas naturais, nas regiões urbanizadas, ainda são mal compreendidos (ALBERTI, 2008).

Para compreendermos os padrões e os processos que se passam com as cidades nos dias atuais, torna-se imprescindível entender como surgiram e evoluíram, suas características e funções e como se organizaram, pois, em última análise, essas são questões que delinearam o modelo urbano atualmente vivenciado (BRUMES, 2001). Alberti (2008) apresenta uma importante síntese sobre estudos que abordam a evolução das cidades como parte da natureza, remontando a história des- de o século $V$ a.C. até os dias atuais. Destaca-se que, durante o último século, esse ramo da ciência tomou forma e evoluiu em várias áreas do conhecimento, incluindo a sociologia, a geografia, a ecologia, a antropologia, a história e o planejamento.

A vida humana civilizada requer a transformação dos ambientes naturais para o atendimento de suas necessidades (OLIVEIRA \& BRITO, 1998), o que torna as cidades sistemas antroponaturais mistos complexos, nos quais os humanos são os agentes dominantes (ALBER$\mathrm{TI}, 2008)$. Como os seres humanos transformam paisagens naturais em ambientes altamente antropizados, criam um novo conjunto de condições ecológicas e alteram os processos ecossistêmicos e suas dinâmicas (ALBERTI, 2008; ALSHARIF \& PRADHAN, 2014). Assim, a cidade e seus equipamentos se constituem em um ambiente artificial, criado e recriado, sob a imposição de três fatores civilizatórios: necessidades, aspirações e possibilidades (OLIVEIRA \& BRITO, 1998).

A urbanização é, hoje, uma das causas antropogênicas mais comuns da perda de terras agrícolas, da destruição de habitats e do declínio da cobertura vegetal natural, visto que ela muda habitats naturais, altera a composição de espécies e os sistemas edáficos e hidrológicos, além de modificar os fluxos de energia e os ciclos de nutrientes (ARAÚJO SILVA et al., 2007; ALBERTI, 2008; WU et al., 2013; PRAMANIK \& STATHAKIS, 2016). A rápida expansão urbana resulta em infraestrutura decadente, aumento descontrolado de assentamentos informais (BHATTA, 2010), efeitos socioeconômicos e ambientais negativos, poluição do ar, da água, do solo e mudanças climáticas nos ecossistemas (WU et al., 2013; GROFFMAN et al., 2016; STEWARD et al., 2017). Tal crescimento também provoca alterações no microclima, surgimento de ilhas de calor e aquecimento global (ARAÚJO SILVA et al., 2007; WU et al., 2013; STEWARD et al., 2017) e, principalmente, degradação de áreas costeiras, com a destruição de diversos ecossistemas (ARAÚJO SILVA et al., 2007).

As áreas urbanas são as regiões mais dinâmicas do planeta (MOELLER, 2005); a expansão constante vem ocorrendo desde o passado e continuará no futuro em todo o mundo, devido ao crescimento populacional (WU et al., 2013; ALSHARIF \& PRADHAN, 2014; 
PRAMANIK \& STATHAKIS, 2016). A expansão urbana é influenciada por uma série de fatores, incluindo aspectos geográficos, demográficos, econômicos, sociais, ambientais e culturais (BHATTA, 2010; JIANG \& YAO, 2010; ABDULLAHI \& PRADHAN, 2016). Devido ao aumento global da população humana e à mudança progressiva mundial de uma economia meramente agrícola para outros tipos de economias de mercado (industrial e de serviços, por exemplo), as cidades têm experimentado uma expansão rápida e muitas vezes descontrolada (PRAMANIK \& STATHAKIS, 2016). O crescimento da população urbana (quer seja por meio de nascimentos ou por meio de movimentos migratórios) decorre principalmente do fato de que a vida nas cidades tem menor custo per capita de fornecimento de água potável, saneamento, energia elétrica, coleta de resíduos e de telecomunicações, e oferece melhor acesso a educação, emprego, cuidados à saúde, serviços sociais, facilidades nos transportes e variedades de bens (ARAÚJO SILVA et al., 2007; WU et al., 2013). Assim, controlar o processo de urbanização e criar o desenvolvimento sustentável é uma questão de sobrevivência humana e requer informações precisas sobre os padrões de crescimento e expansão urbana (WU et al., 2013; BEZERRA, 2013).

Aproximadamente $3 \%$ da superfície da Terra são ocupados por mais da metade da população do planeta, que se encontra concentrada nas cidades, impondo grandes desafios aos governos e aos países diante da crescente urbanização (WU et al., 2013; IBGE, 2017). Nos últimos 200 anos, a população humana mundial aumentou 6 vezes e a população urbana multiplicouse 100 vezes. Em 1900, apenas 9\% da população humana mundial viviam em ambientes urbanos (WORLD BANK, 1984). Esse número aumentou para $30 \%$, até 1950 , para $40 \%$, até 1980 , para $50 \%$, até 2000 , e deverá aumentar para mais de 70\%, até 2050 (WU et al., 2013; PEREIMA NETO, 2014). Cerca de 160 mil pessoas abandonam, todos os dias, as zonas rurais de todo o mundo e se dirigem para as cidades, e, atualmente, quase metade dos habitantes do planeta vive em zonas urbanas (IBGE, 2017). Antes dos anos 1950, a rápida urbanização ocorreu com maior intensidade nos países desenvolvidos, o que resultou em um aumento do desenvolvimento urbano e em uma redução significativa das terras agrícolas (WORLD BANK, 1984). No entanto, nos últimos anos, a conversão do uso e da cobertura da terra, devido às atividades humanas, ocorreu mais rapidamente nos países em desenvolvimento do que no mundo industrializado, com a expansão urbana seguindo a mesma tendência (WU et al., 2013; PEREIMA NETO, 2014; PRAMANIK \& STATHAKIS, 2016).

Tratando-se de Brasil, o processo de urbanização foi mais rápido do que em outras partes do mundo (PEREIMA NETO, 2014). A população urbana, que, em 1950, era de $36,1 \%$, atingiu, em 2010 , a casa dos $84 \%$ (IBGE, 2017). A intensa urbanização que se iniciou no final dos anos 1950 começou a apresentar seus efeitos já nos anos 1960 . O crescimento de áreas metropolitanas brasileiras, a ampliação da rede urbana e o aguçamento de seus problemas marcaram as últimas décadas do século XX (IBGE, 2017). O fenômeno demográfico mais importante desde os anos 1950 (e que ainda está em curso) no Brasil não foi o da alta taxa de crescimento populacional, mas sim a acentuada migração espacial, que é a migração urbana-urbana, a qual ocorre entre municípios com diferentes densidades populacionais em função de diferenciais de renda per capita e oportunidades de trabalho (PEREIMA NETO, 2014). Esse fato também ocorreu e ainda é frequente no sul do estado de Santa Catarina, o que tem provocado o aumento populacional e a expansão urbana de várias cidades-polo, como no caso da cidade de Araranguá.

Até meados da década de 1970, a cidade de Araranguá seguiu a tendência de expansão concêntrica (ESTEVAM et al., 2014), isto é, no sentido centro-periferia (REIS, 2006). No decorrer da segunda metade dos anos 1970, a migração da população rural do extremo sul catarinense para a cidade-polo de Araranguá, em busca de melhor qualidade de vida, adensou-a ainda mais, impondo mudanças em suas estruturas e provocando acentuada expansão urbana. De lá para cá, é perceptível a expansão da cidade e da rede viária sobre locais impróprios à ocupação humana do ponto de vista ambiental. Assim sendo, o presente estudo teve o objetivo de mapear a expansão urbana da cidade de Araranguá, Santa Catarina, no período de 1957 a 2010, e analisar as implicações ambientais dessa expansão sobre os locais com cotas altimétricas baixas e sujeitas a inundações periódicas, áreas úmidas, entorno de nascentes e margens de corpos d'água. 


\section{METODOLOGIA}

\section{A área de estudo}

O município de Araranguá, com área de aproximadamente 304 km², situa-se no extremo sul de Santa Catarina (Figura 1) e sua sede está localizada nas coordenadas $28^{\circ} 56^{\prime} 6^{\prime \prime} \mathrm{S}, 49^{\circ} 29^{\prime} 9^{\prime \prime} \mathrm{W}$, cuja área central se encontra a $13 \mathrm{~m}$ acima do nível do mar (a.n.m.) (IBGE, 2017).

O clima, segundo a classificação climática de Köppen, é enquadrado como Cfa, clima subtropical constantemente úmido e sem estação seca definida (EPAGRI, 2001). Do ponto de vista geomorfológico, a área do município de Araranguá é caracterizada pela presença de uma vasta planície, com a presença de elevações de origem ígnea ou feições sedimentares fanerozoicas isoladas, as quais se destacam na paisagem formando morros testemunhos e ocasionando contrastes altimétricos acentuados. Ocorrem ainda formas de topo plano ou baixos tabuleiros de alturas variáveis, girando em torno de $10 \mathrm{~m}$ na Planície Costeira e alcançando, em alguns terraços inferiores, próximos das elevações testemunhas, de 30 a $80 \mathrm{~m}$ de altitude (SANTA CATARINA, 1991).

O sistema hidrográfico tem como seu principal representante o rio Araranguá, que denomina a própria bacia hidrográfica, formado por duas grandes sub-bacias: a do rio Itoupava e a do rio Mãe Luzia, que se fundem bem próximo à cidade de Araranguá, quando passam a formar o rio que a denomina, desembocando no Oceano Atlântico (ALEXANDRE, 2001).

Os solos do município, de acordo com a Classificação Brasileira de Solos (EMBRAPA, 2006), são principalmente dos tipos: Neossolos Quartzarênicos, Gleissolos (Húmico e Pouco Húmico), Argissolos e Organos-

\section{Coleta e análise de dados}

Os procedimentos desenvolvidos neste estudo envolveram as seguintes etapas: delimitação da área de estudo e épocas a serem analisadas; aquisição de bases cartográficas e imagens aéreas datadas de 1957, 1978 e 2010; delineamento metodológico; e processamento e análise dos dados.

Foi definido que o mapeamento do uso e da cobertura da terra no âmbito do perímetro urbano do município de Araranguá partiria da área ocupada pela malha urbana, em 2010, e que, a partir dessa área física, seria solos. Os Neossolos Quartzarênicos e os Organossolos ocorrem predominantemente junto à Planície Costeira; os Gleissolos estão distribuídos junto à planície de inundação do rio Araranguá; e os Argissolos ocorrem junto às elevações oriundas de morros testemunhas (EPAGRI, 2001).

A cobertura vegetal era originalmente representada pela Floresta Ombrófila Densa, ocorrendo do mar para o continente as Formações Pioneiras ou Restinga (Herbácea, Herbáceo-Arbustiva, Arbustivo-Arbórea e Arbórea), pela Floresta das Terras Baixas (com suas respectivas variações - Floresta ao Longo das Lagoas, Floresta sobre Solos Bem Drenados e Florestas sobre Solos Mal Drenados) e pela Floresta Ombrófila Densa Submontana (IBGE, 2012). Atualmente, a cobertura vegetal do município de Araranguá se encontra representada por fragmentos remanescentes da cobertura original, como resultado das atividades antrópicas desenvolvidas a partir da colonização.

O surgimento e o desenvolvimento de Araranguá se deram a partir de 1848; a região se tornou município em 1880 e contava com uma população humana de 10.730 habitantes (HOBOLD, 1994). Ocorreram desmembramentos do território inicial, ocasionando o surgimento de alguns municípios entre as décadas de 1957 e 2010. Segundo o Censo Demográfico de 2010, a população do município de Araranguá era de 61.630 habitantes, entre os quais $82,41 \%$ residiam na zona urbana. A economia está calcada na produção agrícola, na indústria, na prestação de serviços e no turismo (IBGE, 2017).

efetuado o mapeamento dos anos de 1957 e 1978. A definição das três datas para a análise se deu em função da disponibilidade das fotografias aéreas.

Para a construção da base de dados georreferenciados e o processamento em ambiente SIG, foram utilizados os softwares ArcGIS 10.1 e ArcScene, ambos produzidos por ESRI. Após o processamento e a geração dos mapas temáticos, efetuou-se a análise e a interpretação dos produtos. 

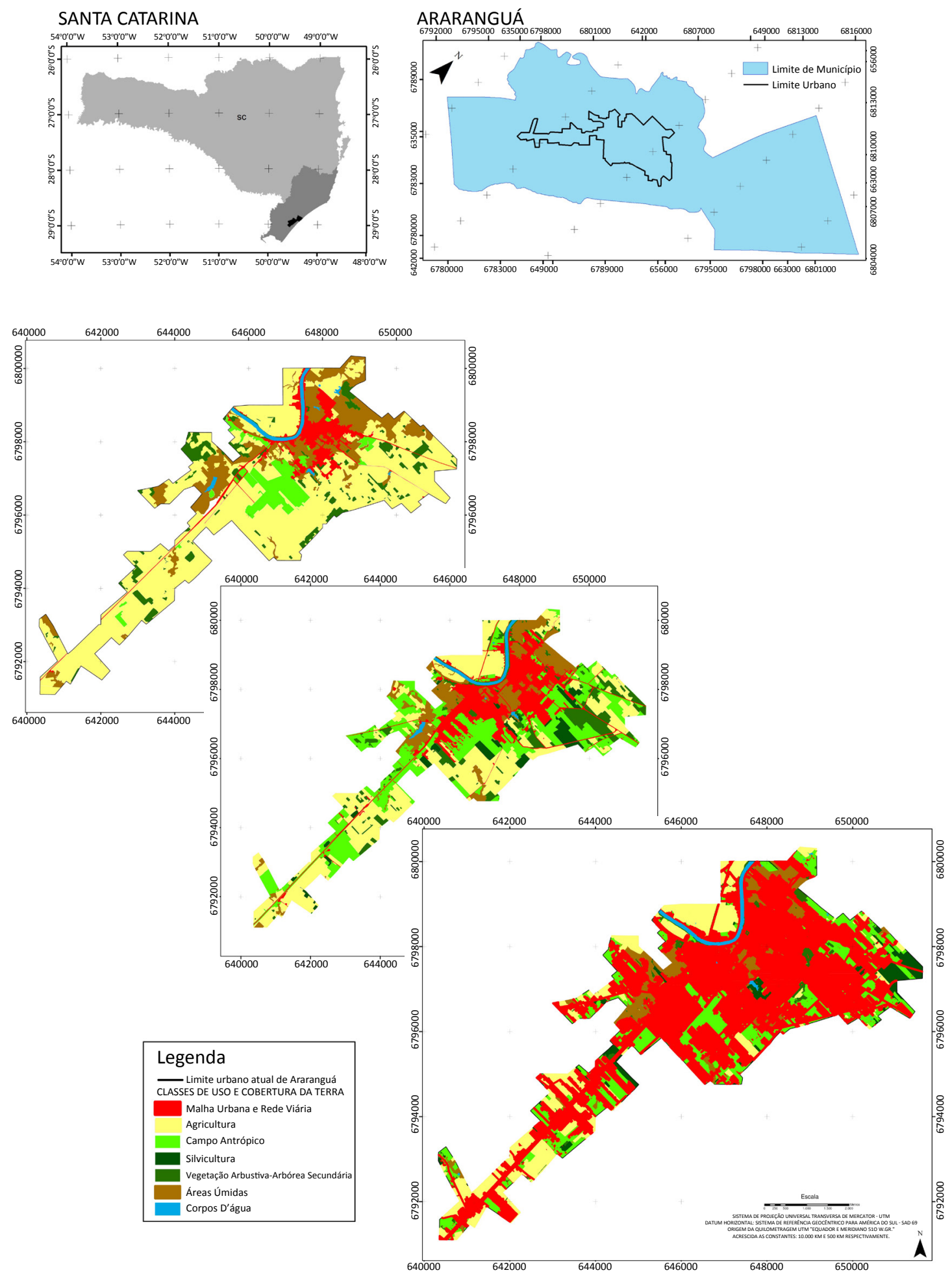

Fonte: autores.

Figura 1 - Mapa de localização da área estudada, evidenciando a expansão urbana da cidade de Araranguá no período de 1957 a 2010 (cor vermelha) sobre as demais formas de uso e cobertura da terra. No canto esquerdo superior encontra-se a imagem do ano de 1957 e no canto direito inferior, a imagem do ano de 2010. 
Os procedimentos para a determinação do uso e da cobertura da terra no âmbito da malha urbana do município de Araranguá (sede) envolveram as seguintes etapas:

- aquisição e georreferenciamento das fotografias aéreas (escala de voo de 1:30.000 e 1:25.000, anos de 1957 e 1978, respectivamente);

- elaboração de mosaicos não controlados para os anos de 1957 e 1978;

- elaboração de ortofocarta composta por fotografias aéreas na escala original de 1:30.000, datadas de 2010, ortorretificadas, georreferenciadas e restituídas para a escala 1:10.000 (o erro aproximado na ortorretificação foi de $8 \mathrm{~m}$ );

- individualização dos polígonos com a digitalização em tela de computador;

- identificação e classificação das formas de uso e cobertura da terra;

- cálculo da área ocupada pelas diferentes classes;

- elaboração do mapa de solos, cuja base cartográfica foi o Mapa de Solos da Unidade de Planejamento Regional Litoral Sul Catarinense - UPR8 (escala 1:250.000), produzido pela Empresa de Pesquisa Agropecuária e de Extensão Rural de Santa Catarina - EPAGRI (2001);

- elaboração do mapa geológico, cujas bases cartográficas foram o Mapa Geológico da Bacia do Rio Araranguá, escala 1:100.000 (KREBS, 2004), e o Mapa Geológico do Quaternário Costeiro do Estado do Paraná e Santa Catarina, escala 1:200.000, produzido pela Companhia de Pesquisa de Recursos Minerais - CPRM (1988);

- elaboração do Modelo Digital do Terreno (MDT), produzido a partir dos pontos cotados lançados sobre a ortofotocarta (escala original de 1:30.000), datada de 2010, ortorretificada, georreferenciada e restituída para a escala 1:25.000; e

- elaboração do mapa de áreas propícias à expansão do perímetro urbano.

Para definição das diferentes classes de uso e cobertura da terra, foi adotada a mesma nomenclatura proposta por Campos et al. (2013), modificada e adaptada à realidade do presente estudo. Na classe 1 , denominada de Malha Urbana e Rede Viária, foram enquadradas a malha urbana propriamente dita, as rodovias pavimentadas e as estradas e ruas não pavimentadas. Na classe 2, denominada de Agricultura, foram agrupadas todas as áreas de cultivo de sequeiro (culturas não irrigadas) e as áreas de culturas irrigadas (cultivo de arroz). A classe 3, denominada de Campo Antrópico, reuniu todas as áreas cobertas por vegetação herbácea rasteira, a qual imprimia nas imagens uma reflectância semelhante aos campos nativos. Cabe aqui ressaltar que na região não ocorre a fitofisionomina do tipo campo nativo (IBGE, 2012). Na classe 4, foram reunidas as áreas de silvicultura de pinus (Pinus spp.) e eucaliptos (Eucalyptus spp.), identificadas principalmente em função da reflectância, da localização e do formato geométrico das manchas. A classe 5 , denominada de vegetação arbustiva-arbórea secundária, reuniu todas as manchas ocupadas por vegetação arbustivo-arbórea, representadas por capoeiras, capoeirões e a mata secundária propriamente dita. Na classe 6 , denominada de áreas úmidas, foram reunidas todas as áreas que se encontravam cobertas por vegetação herbáceo-arbustiva, mas que por sua localização estavam associadas à área de contato entre as formações geológicas Depósitos Fluviolagunares (QHfl) e Depósitos Praiais Marinhos e Eólicos ( $Q P b)$, situadas abaixo da cota altimétrica 2,0 $\mathrm{m}$. Na classe 7, denominada de corpos d'água, foram reunidos o rio Araranguá e os demais corpos d'água (açudes e afloramentos de água) naturais e/ou artificialmente delimitados.

Para efeitos de mapeamento das áreas propícias à expansão do perímetro urbano da cidade de Araranguá, foram identificados no mapa geológico da área de estudo os limites de ocorrência dos $\mathrm{QPb}$ e dos QHfl, que foram tomados, respectivamente, como formações geológicas propícias e impróprias à instalação de construções civis. De acordo com tal identificação, há maior percentual de ocorrência de QHfl a partir de $2 \mathrm{~km}$ do contorno do perímetro urbano de 2010, estabelecendo essa distância como sendo o buffer de estudo para a definição das áreas propícias à expansão urbana. Sobre o mapa geológico foi lançado o buffer de $2 \mathrm{~km}$ de raio e os mapas: de solos, do perímetro urbano do município de Araranguá em 2010, da rede hidrográfica obtida das folhas SH-22-X-B-IV-3 - 2940-3 (Araranguá) e SH-22-X-A-VI-4 - 2939-4 (Turvo), escala 1: 50.000 , e do MDT. Sobre a rede hidrográfica foram 
projetadas, ainda, as áreas de preservação permanente (APPs) conforme a Lei $\mathrm{n}^{\circ} 12.651$, de 25 de maio de 2012 (BRASIL, 2012). O cruzamento de todos esses planos de informações gerou um mapa temático que esboça as áreas favoráveis à expansão do perímetro urbano da cidade de Araranguá.

\section{RESULTADOS}

A escala e a qualidade das fotografias aéreas analisadas permitiram a identificação de seis classes de uso e cobertura da terra, para o ano de 1957, e de sete classes, para os anos de 1978 e 2010 (Figura 1).

A expansão da malha urbana e da rede viária de Araranguá, assim como a expansão e/ou a retração das demais formas de uso e cobertura da terra, identificadas nas três datas analisadas (1957, 1978 e 2010), encontram-se sintetizadas na Tabela 1 , na qual se evidencia que: as classes 1 e 3 tiveram suas áreas expandidas, enquanto as classes: 2, 5 e 6 sofreram drástica retração no período de 1957 a 2010. A maIha urbana sofreu um incremento na ordem de 6,92 vezes, ou seja, expandiu-se de 203,63 ha (em 1957) para 1408,91 (em 2010) e o campo antrópico aumentou na ordem de 3,48 vezes, passando de 182,09 ha, em 1957, para 634,34 ha, em 2010. As áreas agrícolas sofreram uma redução na ordem de 4,55 vezes, passando de 1708,52 ha, em 1957, para 391,59 ha, em 2010; a vegetação arbustiva-arbórea secundária foi submetida à redução na ordem de 2,51 vezes, passando de 221,35 ha, em 1957, para 88,03 ha, em 2010; e as áreas úmidas sofreram redução de 2,14 vezes, passando de 466,08 ha, em 1957, para 217,99 ha, em 2010. A classe 4, que não está representada em 1957, aparece em 1978 ocupando 4,89\% da área mapeada, representatividade mantida em 2010, enquanto a classe 7 sofreu uma redução na ordem de $12 \%$, passando de 46 ha, em 1957, para 40, 54 ha, em 2010.

No ano de 1957 (Tabela 1), a classe 2 era dominante, seguida pelas classes 6, 5, 1, 3 e 7. Nas imagens aéreas de 1957 não foi possível detectar a presença da classe 4 na área estudada, a qual é nitidamente identificada nos anos de 1978 e 2010 (Figura 1), em decorrência da sua localização e do formato geométrico (geralmente retangular, trapezoidal ou de quadrado) que assume na paisagem (FLORENZANO, 2002).

No ano de 1978, a classe de uso e cobertura da terra dominante ainda era a classe 2 , seguida pelas classes 3 , 1, 6, 5, 4 e 7 (Tabela 1).

No ano de 2010, observam-se mudanças drásticas na área estudada (Tabela 1), quando a classe 1 passou a ser a forma de uso e cobertura da terra dominante, seguida pelas classes $3,2,6,45$ e 7 .

Tabela 1 - Classes de uso e cobertura da terra, área ocupada (ha) e percentual de contribuição de cada classe nas três datas analisadas (1957, 1978 e 2010), em relação aos 2899,67 ha ocupados pelo perímetro urbano do município de Araranguá, Santa Catarina, em 2010.

\begin{tabular}{|l|c|c|c|c|c|c|}
\hline \multirow{2}{*}{$\begin{array}{l}\text { Classes de uso e } \\
\text { cobertura da Terra }\end{array}$} & \multicolumn{4}{|c|}{ Área ocupada (ha) e percentual de contribuição (\%) } \\
\cline { 2 - 7 } & \multicolumn{2}{|c|}{1957} & \multicolumn{2}{|c|}{1978} & \multicolumn{2}{|c|}{2010} \\
\hline & ha & $\%$ & ha & $\%$ & ha & $\%$ \\
\hline 1. Malha urbana e rede viária & 203,63 & 7,02 & 472,11 & 16,28 & 1408,91 & 48,59 \\
\hline 2. Agricultura & 1780,52 & 61,40 & 910,93 & 30,77 & 391,59 & 13,59 \\
\hline 3. Campo antrópico & 182,09 & 6,28 & 771,11 & 26,29 & 634,34 & 21,88 \\
\hline 4. Silvicultura & - & 0,00 & 114,22 & 4,89 & 118,38 & 4,08 \\
\hline 5. Vegetação arbustiva-arbórea secundária & 221,35 & 7,63 & 267,71 & 9,23 & 88,03 & 3,04 \\
\hline 6. Áreas úmidas & 466,08 & 16,07 & 322,11 & 11,11 & 217,99 & 7,52 \\
\hline 7. Corpos d'água & 46,00 & 1,59 & 41,51 & 1,43 & 40,54 & 1,40 \\
\hline Total & 2899,67 & 100,00 & 2899,70 & 100,00 & 2899,67 & 100,00 \\
\hline
\end{tabular}

Fonte: autores. 
A expansão e a retração temporal das classes de uso e cobertura da terra da área em estudo, ao longo do período analisado, estão sintetizadas na Figura 2.

Observa-se nitidamente, pela Figura 2, que a malha urbana e o campo antrópico evidenciaram um crescimento contínuo e de forma exponencial, este último pelo menos no período de 1957 a 1978. As áreas úmidas e a vegetação florestal secundária, por sua vez, evidenciaram retração linear, enquanto as áreas agrícolas sofreram uma retração exponencial em suas representatividades ao longo do período estudado.

O mapeamento das unidades litológicas permitiu a identificação da presença de três unidades distintas na área estudada (Figura 3): a unidade litológica dos $\mathrm{QHfl}$; a unidade litológica dos $\mathrm{QPb}$; e a unidade litológica Formação Rio do Rastro (PTRrr), as quais ocupavam, respectivamente, $19,10,79,21$ e $1,69 \%$ do perímetro urbano da cidade de Araranguá, em 2010. A Figura 3 traz, ainda, as áreas propícias à expansão urbana, considerando-se os aspectos geológicos, edáficos, altimétricos e de proteção legal dos corpos d'água.

O MDT, não apresentado neste estudo, mas disponível em Marcon (2015), revela que a variação altimétrica da área estudada oscilou de 0,20 a $90 \mathrm{~m}$ acima do nível do mar, evidenciando que $50,5 \%$ da área do perímetro urbano do município se encontram nas classes de altitude de 20 a $30 \mathrm{~m}$. Dos 49,5\% restantes, 1,5 e 48\%, respectivamente, se encontram nas classes de altitude maiores do que $30 \mathrm{~m}$ e menores que $20 \mathrm{~m}$, sendo que praticamente metade dos $48 \%$ se encontra distribuída nas cotas altimétricas mais baixas de até $5,0 \mathrm{~m}$.

A Figura 4 traz, de forma sintetizada, uma proposta de análise interdisciplinar das causas do crescimento e da expansão urbana da cidade de Araranguá e as suas respectivas consequências sobre os ecossistemas naturais e antrópico.

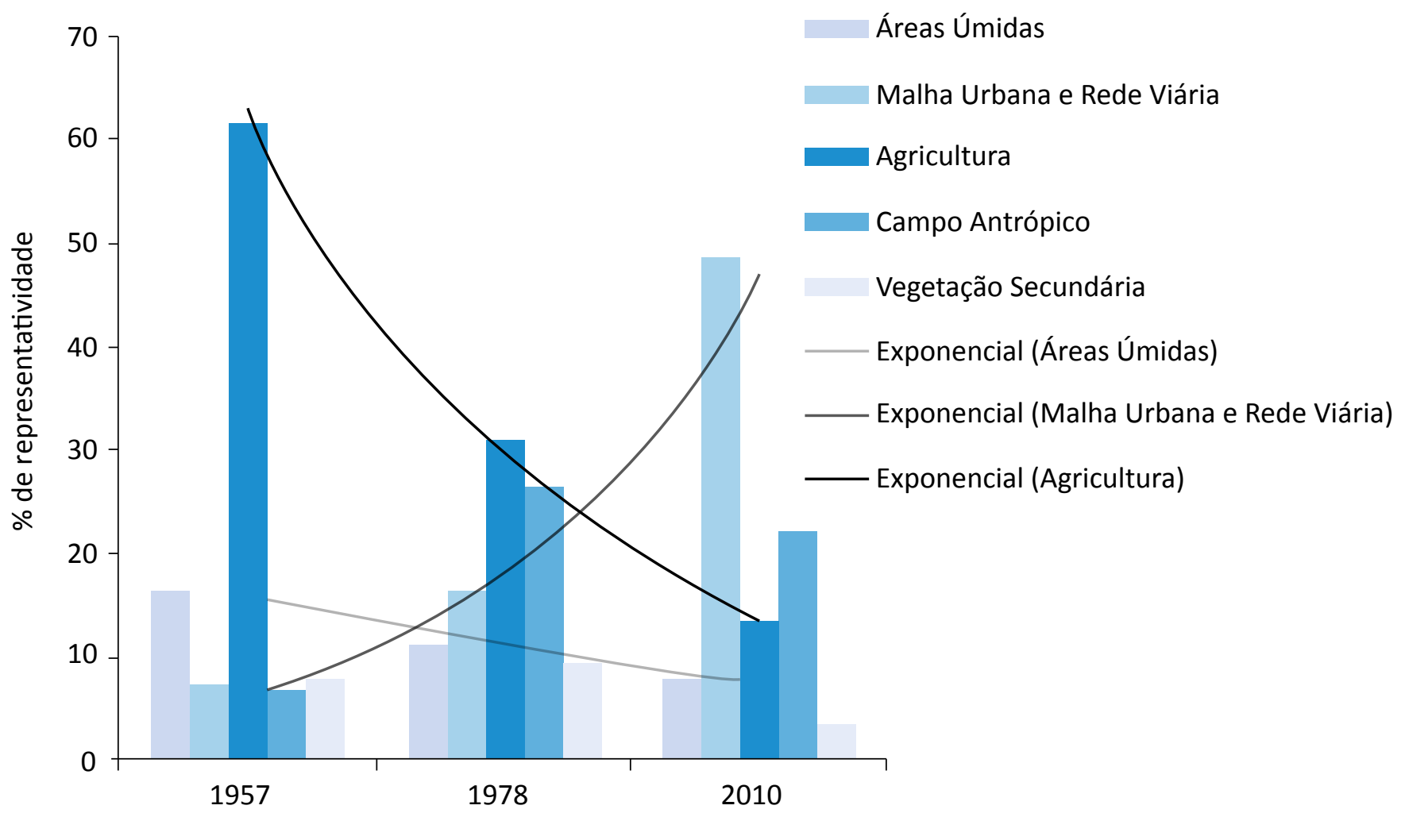

Anos

Figura 2 - Síntese da evolução temporal da expansão urbana da cidade de Araranguá, entre os anos de 1957 e 2010, sobre as classes de uso e cobertura da terra que sofreram retração. 
SANTA CATARINA

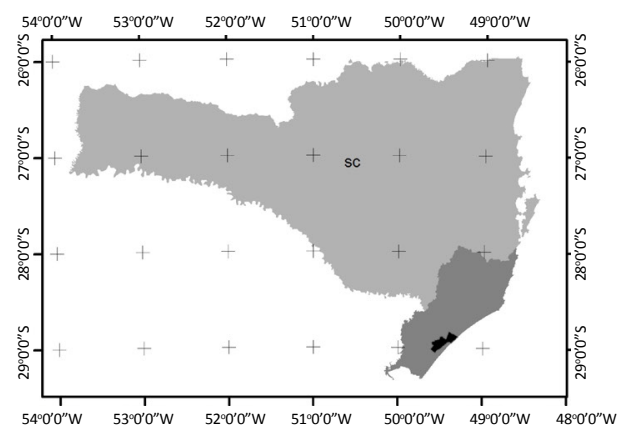

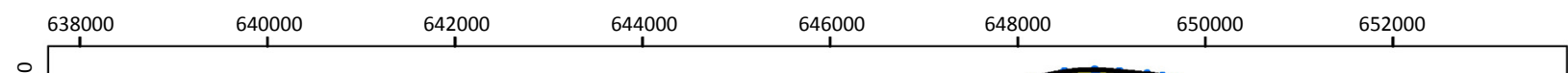

ARARANGUÁ

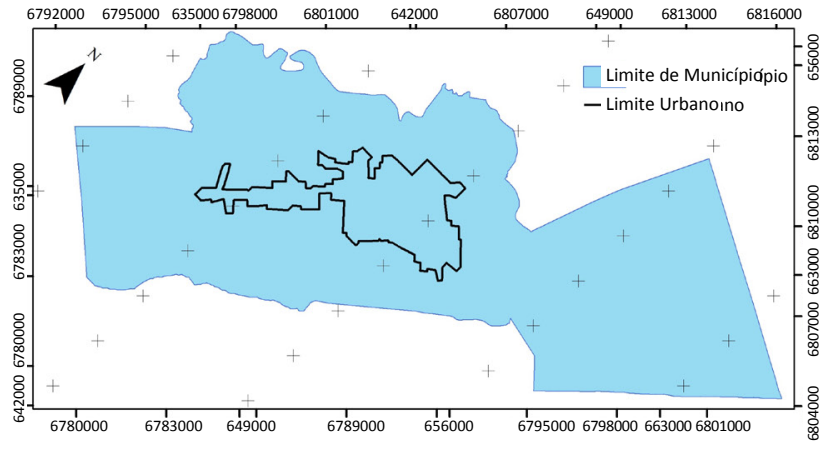

:

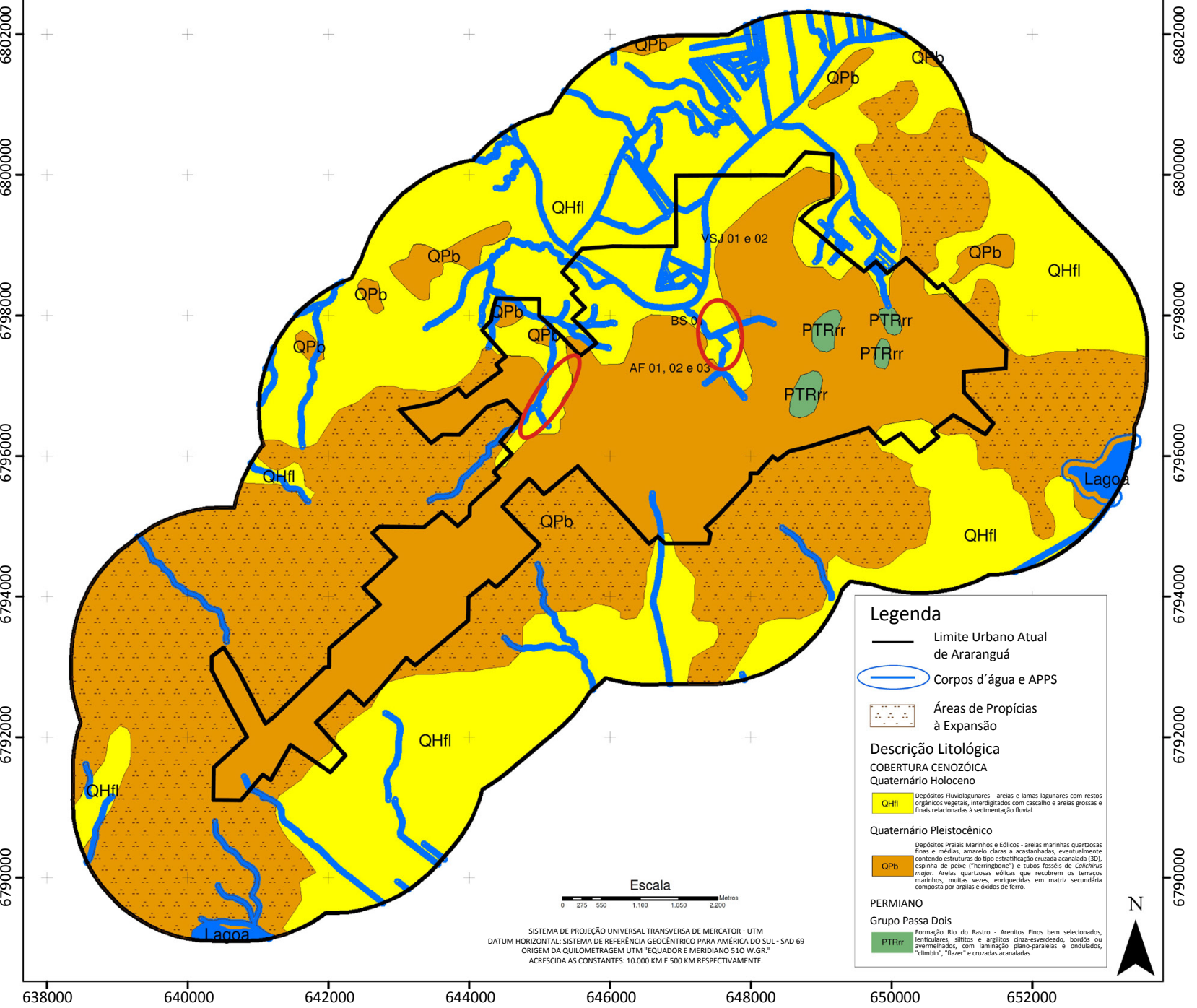

Fonte: autores.

Figura 3 - Mapa geológico da área estudada, com delineamento das áreas propícias à expansão urbana da cidade de Araranguá, segundo as características sedimentológicas e a presença de áreas de preservação permanente definidas por Lei, cujas cotas altimétricas são inferiores a 3,0 m a.n.m. Os dois círculos vermelhos indicam as duas áreas impróprias à expansão urbana e ocupadas pela malha urbana, localizadas na região central da cidade e no Bairro Jardim Cibele. 


\section{DISCUSSÃO}

As relações estabelecidas entre o homem e seu ambiente imediato materializam-se pela exploração dos recursos naturais que refletem o uso e a cobertura da terra, configurando as paisagens. $O$ uso da terra resulta em um mosaico de formas regulares e irregulares na paisagem, que são perceptíveis segundo a escala de observação e o observador. As feições impressas na paisagem revelam assim o modus vivendi de uma determinada população em um determinado tempo e espaço.

A análise espacial da dinâmica da expansão urbana é muito importante nos estudos urbanos, sobretudo para a gestão pública. Vários autores abordaram a temática da expansão urbana, discutindo o ambiente urbano, o desenvolvimento urbano, a detecção de mudanças espaciais, a modelagem e a gestão urbana (ABDULLAHI et al., 2015, ALSHARIF \& PRADHAN, 2014; ALSHARIF et al., 2015; DADRAS et al., 2015).

O perímetro urbano da cidade de Araranguá, no período de tempo estudado, se expandiu em torno de 6,5 vezes. Nesse mesmo período, o Brasil se tornou urbano: a população total evidenciou crescimento na ordem de 4,7 vezes, passando de 41,2 milhões de habitantes, em 1940, para 195,2 milhões de habitantes, em 2010. A população urbana que, em 1940 , era de $31,8 \%$ passou para $84,35 \%$, em 2010 . Enquanto a população total quase quintuplicou, a população urbana cresceu na ordem de 15,57 vezes, passando de 12,8 milhões, em 1940, para 160,9 milhões, em 2010 (IBGE, 2017).

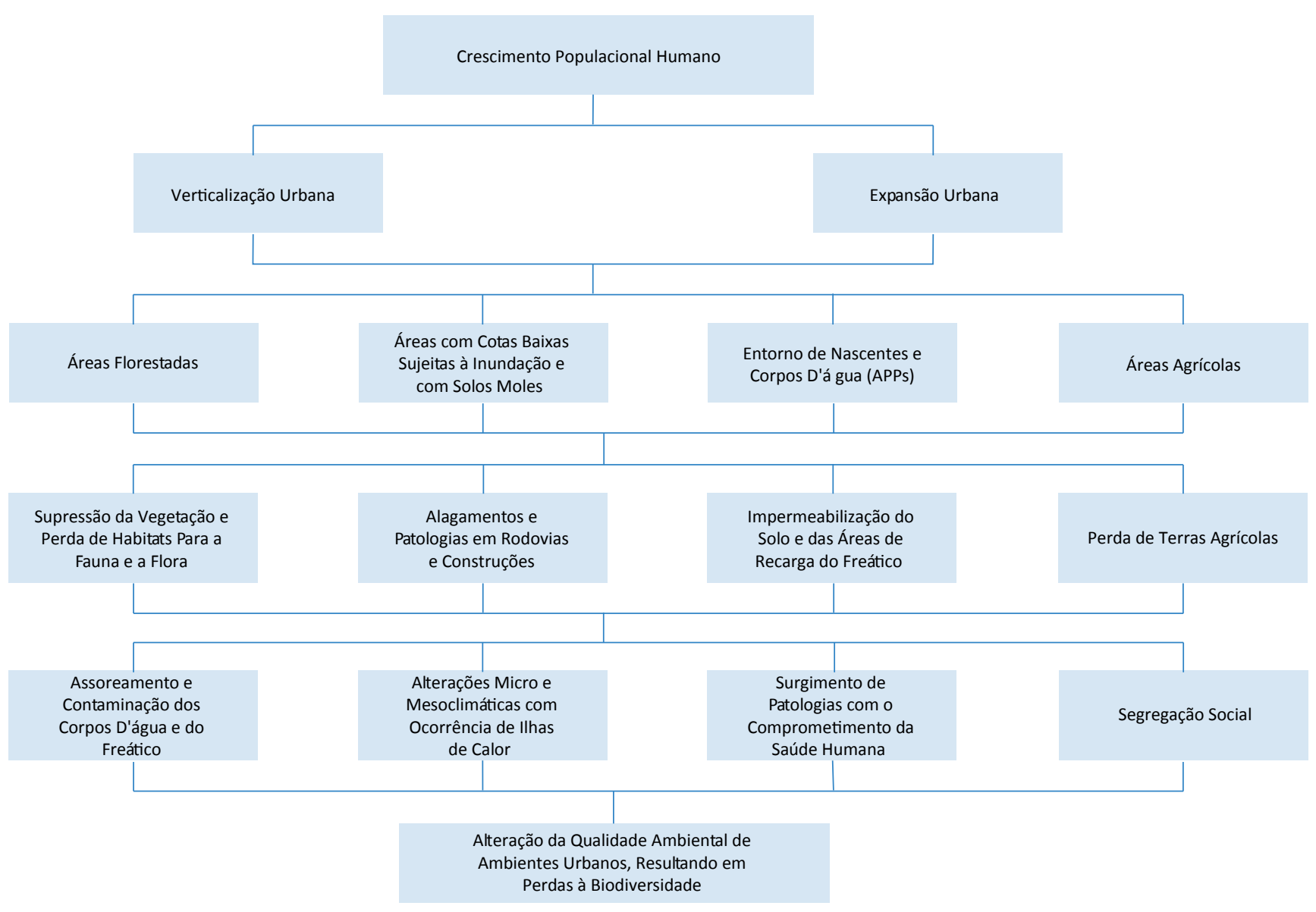

APPs: áreas de preservação permanente.

Figura 4 - Proposta de análise interdisciplinar das causas do crescimento e expansão urbana da cidade de Araranguá e as respectivas consequências sobre os ecossistemas naturais e o sistema antrópico. 
A forma exponencial de urbanização mundial, citada por Antrop (2004), o qual a caracteriza como um processo complexo de mudança de estilos de vida rural para urbano, a partir do final do século XIX, ocorreu igualmente na cidade Araranguá entre 1957 e 2010. Estevam et al. (2014) assinalam que a cidade de Araranguá, pelo fato de se caracterizar como cidade-polo da Associação de Municípios do Extremo Sul Catarinense (AMESC), atrai um contingente populacional muito grande dos municípios vizinhos, o que fez com que sua população humana saltasse de 26.000, no ano de 1970 , para 61.000 habitantes, em 2010, evidenciando um crescimento contínuo ao longo desse período.

A dinâmica das classes de uso e cobertura da terra do município de Araranguá, observada ao longo do período estudado, retrata, de modo geral, o comportamento humano no decorrer do processo de implantação e de expansão das cidades. As áreas mais nobres são ocupadas e, à medida que a população aumenta, a malha urbana avança sobre outras áreas (ALSHARIF et al., 2015). Assim, percebe-se que a atitude de executar a drenagem dos terrenos úmidos provoca o rebaixamento do lençol freático, as espécies vegetais dominantes são substituídas por outras menos tolerantes à saturação e ocorre a substituição da cobertura vegetal arbustiva-arbórea por uma cobertura herbácea de campo antrópico. Na sequência, a malha urbana invade e suplanta as áreas úmidas e sua expansão passa a ocupar também terras agrícolas.

A sede do município está localizada entre as cotas 10 e $20 \mathrm{~m}$, com altitude de $13 \mathrm{~m}$ a.n.m. na área central (IBGE, 2017). Mas existem áreas cujas cotas altimétricas são inferiores a 3,0 m e que estão sendo ocupadas cada vez mais pela rede viária, seguida pela instalação de edificações. Essas atitudes agravam ainda mais os problemas ambientais, pois, para alcançar as cotas altimétricas desejadas, os proprietários recorrem ao aterramento das áreas de nascentes e áreas úmidas. Duas áreas com tais características foram identificadas neste estudo e estão indicadas na Figura 3. Em ambos os casos, ultrapassando todo o limiar do bom-senso, da ética e do próprio poder de polícia das administrações públicas municipal, estadual e federal, a expansão da área urbana está se dando sobre locais impróprios, inclusive em APPs, que acabam continuamente recebendo aterramentos. A primeira área está localizada na região central da cidade, em trechos das avenidas Sete de Setembro e XV de Novembro, onde as cotas altimétricas são mais baixas, e a segunda está localizada entre a margem do antigo traçado da BR 101 e a margem do açude Manoel Angélica, no bairro Jardim Cibele, ambas as áreas estão sob uma forte pressão imobiliária.

Seguindo a tendência de expansão horizontal das cidades que ocorre sobre as áreas rurais, há necessidade de se refletir sobre o planejamento da expansão da cidade de Araranguá. Esta reflexão se justifica pela possibilidade da interferência antrópica contaminar as nascentes que se encontram em áreas circundantes ao atual perímetro urbano, assim como de canalizar córregos interferindo no fluxo e qualidades das águas superficiais e subsuperficiais. Ainda mais a cidade de Araranguá, que se localiza, quase que em sua totalidade, sobre solos do tipo AQd - Neossolos, os quais são constituídos por areias quartzosas e, portanto, mais suscetíveis à erosão, característica intensificada nos casos de enxurradas em locais que sofreram cortes ou aterros, onde o solo se apresenta sem cobertura vegetal. Ademais, a Lei Federal $n^{\circ}$ 12.651/2012 (BRASIL, 2012), que trata do Código Florestal Brasileiro, reconhece o entorno de nascentes, de cursos d'água, de lagos e lagoas, como APPs, devendo, portanto, ser respeitadas, para que possam cumprir com suas funções ambientais.

Com a expansão urbana, a exposição do solo leva ao carregamento dos sedimentos, que é ampliado nas enxurradas e é direcionado às bacias de captação, as quais são caracterizadas por cotas inferiores, curvas de nível aproximadamente concêntricas e microrrelevo em forma de bacia. Essas bacias sofrerão assoreamento ao longo do tempo, tendo sua profundidade útil reduzida, o que favorece a ocorrência de alagamentos em eventos de chuvas torrenciais a montante da bacia, ampliando a área de inundação no seu entorno (OLIVEIRA \& BRITO, 1998). Por outro lado, além da exposição do solo à erosão, a crescente impermeabilização no espaço urbano, principalmente em virtude da pavimentação asfáltica, aumenta a quantidade e a velocidade do escoamento superficial, reduz a recarga dos aquíferos, amplia o processo de erosão, levando mais sedimentos para os canais, assoreando-os e contribuindo para as inundações e os alagamentos (FELIPPE \& MAGALHÃES JUNIOR, 2009; ALVES \& FERREIRA, 2016).

Alagamentos em locais que apresentam as cotas mais baixas (inferiores a $2 \mathrm{~m}$ a.n.m.) chamam a atenção, evidenciando problemas na expansão temporal da ci- 
dade. Percebe-se que os locais sujeitos a esse tipo de ocorrência se encontram em antigas áreas úmidas da cidade de Araranguá, como, por exemplo, a esquina das avenidas Coronel João Fernandes e Capitão Pedro Fernandes, no centro da cidade. Esse local é, desde a década de 1980, continuamente submetido a obras de drenagem e de ampliação do diâmetro dos drenos; a partir de meados dos anos 1970, houve uma intensa expansão da malha urbana sobre áreas úmidas e com cotas baixas, por meio da canalização parcial de um curso d'água. Na sequência da expansão urbana, essa área vem sendo submetida à intensa verticalização, o que causa transtornos cíclicos devido aos alagamentos em épocas de enxurradas. Mais uma vez, são observadas as interferências antrópicas refletindo negativamente sobre a natureza. As áreas a montante e no entorno desse local deveriam passar por processo de desapropriação, com restauração ambiental concomitante, para que a natureza pudesse se recompor e cumprir sua função.

Tendo em vista que o proprietário que realiza o aterro de seu terreno para edificar não percebe o contexto geral do entorno, há a necessidade de interferência do poder público para que esse processo seja orientado, evitando, assim, a terraplenagem e a expansão urbana sobre áreas indicadas à preservação. A transformação da paisagem local só pode ser compreendida quando identificada no contexto geral relacionando-se as suas dinâmicas (ANTROP, 2004). É importante observar ainda que as áreas úmidas da cidade de Araranguá, com cotas inferiores a 3,0 m, e também as áreas de transição entre camadas geológicas desempenham papel relevante, influenciando no equilíbrio de recarga do lençol freático. Se as águas pluviais podem ser conduzidas até esses locais e armazenadas por um período de tempo maior, o lençol freático as assimilará aos poucos, garantindo, com isso, a reserva de águas subterrâneas (DE ANDRADE \& ROMERO, 2005).

Ainda mais, as edificações de diversos usos acabam drenando nascentes, provocando o desaparecimento destas (FELIPPE \& MAGALHÃES JUNIOR, 2009). Na cidade de Araranguá, o abastecimento de água potável tem como principal fonte o Açude Valter Belizoni, que ocupa uma área de 2,60 ha (SAMAE, 2017). Comparando-se os mapas temáticos de uso e cobertura da terra do ano de 1957 e 1978 (Figura 1) percebe-se que as formas de uso e cobertura da terra do tipo campo antrópico e agricultura, existentes no entorno e mais precisamente a montante do açude, não sofreram mudança significativa. De outro modo, confrontando-se o mapa temático de uso e cobertura da terra do ano 2010 (Figura 1) com os anteriores, nota-se a expansão urbana a montante e no entorno deste corpo d'água, onde houve a substituição das formas de uso e cobertura da terra dos tipos agricultura e campo antrópico existentes pela malha urbana e rede viária.

A transformação do entorno do Açude Belizoni em área urbana deu a possibilidade para a edificação, porém isso pode comprometer a preservação da qualidade da água. Proteger somente as nascentes não seria a meIhor alternativa, mas também suas áreas de recarga. A nascente, sendo um afloramento de lençol freático, em caso de comprometimento, conduzirá ao lençol este comprometimento. Para recuperá-la é necessária a intervenção no processo de infiltração e percolação, para não serem alterados os padrões dos fluxos subterrâneos e manter assim o equilíbrio hidrológico (FELIPPE \& MAGALHÃES JUNIOR, 2009).

Na região do entorno ao Açude Belizoni, como se pode constatar pela Figura 1, é verificada acentuada expansão da malha urbana no período de 1978 a 2010. Falhas na canalização de esgoto ou no próprio sistema de tratamento residencial poderão ocorrer e, com isso, ocasionar infiltrações nocivas no solo e no subsolo. A problemática consiste em que a água do açude supre $70 \%$ do abastecimento para consumo da cidade (SHEIBE, 2010). Outra forma de contaminação é por meio das frequentes enxurradas e dos consequentes alagamentos na área urbana da cidade de Araranguá, os quais podem provocar complicações no âmbito da saúde pública, em decorrência da contaminação da água com esgotos, lixos e dejetos. Essa contaminação poderá ocorrer superficialmente ou em maior escala, quando a infiltração dessa água no solo atingir o lençol freático, refletindo inclusive na recarga do Açude Belizoni.

Por outro lado, áreas com solos moles, áreas úmidas, cotas baixas, entorno de nascentes e de corpo d'água que formam as bacias de captação de águas pluviais também estão sujeitas às contaminações acima citadas, pois também estão sendo ocupadas pela maIha urbana e pela rede viária. Nessas áreas, possíveis agravantes, além das contaminações da água superficial e subterrânea, poderão ocorrer, tais como patologias em edificações e infraestruturas (HIGASHI, 2006; 
TOMINAGA \& AMARAL, 2011). Esses autores assinalam que, ao se edificar sobre áreas que apresentam em seu perfil solos moles com espessuras e/ou cotas relevantes, as soluções técnicas mais seguras remetem às estacas, sendo que das fundações superficiais somente o radier é o mais utilizado. O carregamento externo do solo que apresenta esse perfil não ocorre de forma rápida, pois é relativo ao tempo das etapas construtivas da obra. Sendo assim, as argilas moles que estão sob a edificação, por apresentarem baixa permeabilidade, são drenadas lentamente e, com isso, ocorre o adensamento do solo, até mesmo depois de alguns anos. Esse adensamento é responsável por grande parte dos problemas em fundações.

Uma das patologias que podem ser verificadas em consequência da ocorrência citada no parágrafo anterior são trincas e ondulações perceptíveis na camada asfáltica, principalmente nas avenidas Sete de Setembro e Quinze de Novembro, em consequência do adensamento do solo. Essas duas avenidas são os principais acessos ao centro urbano da cidade de Araranguá, e, para viabilizar suas construções, houve a necessidade de executar aterros sobre base do tipo esteira de eucaliptos nos trechos que ultrapassam regiões com cotas baixas, com o agravante da presença de QHfl.

As classes sociais com melhores condições financeiras que constroem nessa área podem realizar investigações sobre o solo e adotar solução técnico-financeira compatível com a edificação, garantindo, assim, a sua estabilidade e evitando patologias. Porém, cabe aqui ressaltar que a cidade poderá se expandir para áreas com características geotécnicas semelhantes, não necessariamente atraentes ao comércio/prestação de serviços e, em virtude disso, não apresentar expressiva especulação imobiliária condicionando preços inferiores aos lotes. A não relevância comercial desses terrenos conduz, principalmente, a classe de baixa renda para os mesmos, gerando a segregação social (ARAUJO SILVA et al., 2007).

A tecnologia e o poder financeiro fazem com que as cidades cresçam e se expandam para além dos limites de sua capacidade natural. Para manter-se o equilíbrio ambiental, é imprescindível que os limites de ocupação do território, assim como os limites do que o sistema natural pode nos oferecer, sejam conhecidos, para manter sua capacidade de autorregulação e só assim escolher ou definir as tecnologias a serem utilizadas
(NUCCl, 2008). O mapeamento das áreas propícias à expansão da malha urbana de Araranguá (Figura 3) evidencia que, do ponto de vista geológico, os QPb oferecem melhores condições geológicas para edificação, sendo menos problemáticos com relação às fundações.

O cruzamento dos diversos mapas temáticos gerados aponta para a necessidade da verificação de ocorrência de nascentes que se encontram em vários locais indicados como próprios para a expansão urbana. Esses locais, segundo o Código Florestal Brasileiro, devem ser respeitados como APPs (BRASIL, 2012). Concomitantemente, cotas baixas e áreas de contato entre os $\mathrm{QPb}$ e os $\mathrm{QHfl}$ devem ser respeitadas, ou seja, evitadas para a expansão, mesmo não havendo a possibilidade de alagamentos provocados pelo rio Araranguá, pois são áreas suscetíveis ao afloramento do lençol freático.

As dificuldades encontradas ao estudar as possíveis áreas de expansão fazem com que fique a sugestão de se compor uma equipe interdisciplinar, para que essas dificuldades sejam ampla e tecnicamente analisadas, de forma a oferecer subsídios de planejamento à gestão territorial. Mais recentemente, uma nova abordagem tem sido usada no estudo das cidades: a tentativa de desenvolvimento de estudos interdisciplinares (ALBERTI, 2008). Partindo desse pressuposto, certamente a indicação de áreas propícias à expansão urbana poderá sofrer alterações. $O$ trabalho interdisciplinar levará a um produto que, pela abrangência de itens abordados, propicia à sociedade uma maior segurança do que quando desenvolvido de forma disciplinar, ainda que em equipe. A inobservância das condicionantes ambientais sob o ponto de vista interdisciplinar pode resultar em custos públicos onerosos, inclusive com invasão de APPs, como já vem acontecendo em várias partes do mundo, conforme assinalam alguns autores (GROFFMAN et al., 2016; WU et al., 2013), e em cidades brasileiras (SALLES et al., 2013; MARCON, 2015).

Outra alternativa de expansão para a cidade de Araranguá, devido ao crescimento populacional, é o crescimento vertical. Atualmente, verifica-se que essa cidade está em processo de verticalização; todavia, não se visualiza caracterização de adensamento de edifícios. Contanto que a cidade siga essa tendência, cabe ressaltar a necessidade de se manter, entre outros, espaços para recreação e bem-estar, espaços livres para circulação e arborização urbana apropriada, mitigando, assim, a ocorrência das possíveis ilhas de 
calor. Apesar de ser vantajosa para a administração pública, a concentração de edifícios em locais onde já existe infraestrutura levará à sobrecarga na estrutura urbana. Diante disso, há a necessidade de encontrar a relação adequada entre o tamanho da cidade e as suas ampliações. É necessário calcular a equação no perímetro urbano que relaciona lotes edificados e lotes desocupados (MOURA \& NUCCI, 2009).

\section{CONCLUSÕES}

A malha urbana da cidade de Araranguá, no período estudado, evoluiu de forma aproximada a exponencial, avançando, sobretudo, sobre as áreas agrícolas, as áreas úmidas e a vegetação arbustiva-arbórea secundária. $\mathrm{O}$ avanço sobre as áreas úmidas resultou nitidamente em problemas de alagamentos que são cada vez mais frequentes.

As áreas úmidas próximas ao centro da cidade são cada vez mais ocupadas para fins comerciais e de prestação de serviços e para residências de alto padrão, enquanto aquelas que estão mais distantes do centro são utilizadas para diversas finalidades, cujas construções apresentam um padrão inferior àquele verificado na região central, o que segrega, em algum grau, a população que as utiliza.

A constatação de áreas problemáticas com alagamentos em perímetro urbano comprovou o que a literatura alerta: o avanço sobre APPs, mesmo quando apoiado em tecnologia, reproduz situações muitas vezes emergenciais para a gestão pública.
A possibilidade de expansão da malha urbana está reservada à área de ocorrência da formação geológica dos $\mathrm{QPb}$, por apresentar uma relação custo-benefício menor em comparação à formação geológica dos QHfl. Deve-se, contudo, interpretar essa indicação com reservas, pois outros aspectos técnico-ambientais precisam ser considerados, como a escala em que foi efetuado o presente estudo, o respeito às faixas de APPs definidas por lei, a cota altimétrica e as áreas de contato entre as duas formações geológicas em que ocorrem as nascentes.

O uso dos Sistemas de Informação Geográfica (SIGs) foi de fundamental importância para a análise multitemporal e para entender as transformações das classes de uso e cobertura da terra. $\mathrm{O}$ rápido avanço da maIha urbana de Araranguá sobre as áreas úmidas, assim como a degradação ambiental verificada, alerta para a urgência de uma tomada de decisão que deve ter por base os estudos desenvolvidos sob a óptica da interdisciplinaridade, assim como a revisão urgente do Plano Diretor Municipal.

\section{REFERÊNCIAS}

ABDULLAHI, S.; PRADHAN, B. Sustainable brownfields land use change modeling using GIS-Based weights-of-evidence approach. Applied Spatial Analysis and Policy, v. 9, n. 1, p. 21-38, 2016.

ABDULLAHI, S.; PRADHAN, B.; JEBUR, M. GIS-based sustainable city compactness assessment using integration of MCDM, Bayes theorem and RADAR technology. Geocarto International, v. 30, n. 4, p. 365-387, 2015.

ABUTALEB, K.; AHMED, F. Modeling of urban change using remote sensing data and cellular automata technique. Arabian Journal of Geosciences, v. 9, n. 15, p. 656-666, 2016.

ALBERTI, M. Advances in urban ecology: integrating humans and ecological processes in urban ecosystems. New York: Springer, 2008.

ALEXANDRE, N. Z. Análise integrada da qualidade das águas da Bacia do Rio Araranguá (SC). 288 f. Dissertação (Mestrado) - Universidade Federal de Santa Catarina, Florianópolis, 2001.

ALSHARIF, A. A.; PRADHAN, B. Urban sprawl analysis of Tripoli Metropolitan city (Libya) using remote sensing data and multivariate logistic regression model. Journal of the Indian Society of Remote Sensing, v. 42, n. 1, p. 149-163, 2014. 
ALSHARIF, A. A.; PRADHAN, B.; MANSOR, S.; SHAFRI, H. Z. M. Urban expansion assessment by using remotely sensed data and the relative Shannon entropy model in GIS: a case study of Tripoli, Libya. Theoretical and Empirical Researches in Urban Management, v. 10, n. 1, p. 55, 2015.

AL-SHALABI, M.; BILLA, L.; PRADHAN, B.; MANSOR, S.; AL-SHARIF, A. A. A. Modelling urban growth evolution and land-use changes using GIS based cellular automata and SLEUTH models: the case of Sana'a metropolitan city, Yemen. Environmental Earth Sciences, v. 70, n. 1, p. 425-437, 2012.

Al-SHALABI, M.; PRADHAN, B.; MANSOR, S.; ALTHUWAYNEE, O.; BILLA, L. Manifestation of remote sensing data in modeling urban sprawl using the SLEUTH model and brute force calibration: a case study of Sana'a City, Yemen. Journal of the Indian Society of Remote Sensing, v. 41, n. 2, p. 405-416, 2013.

ALVES, G. M. R.; FERREIRA, M. F. M. Uso do solo em áreas de preservação permanente (APP) na bacia do córrego do Pântano, município de Alfenas-MG. Revista de Geografia, v. 6, n. 4, p. 329-337, 2016.

ANTROP, M. Landscape change and the urbanization process in Europe. Landscape and Urban Planning, v. 67, n. 1-4, p. 9-26, 2004.

ARAÚJO SILVA, M. N. A.; COPQUE, A. C. D. S. M.; GIUDICE, D. S. Consequências das transformações ambientais no processo de expansão das cidades - o exemplo de Salvador/Bahia. In: ENCONTRO LATINO AMERICANO DE GEÓGRAFOS, 2007, Bogotá. Anais... 2007. Disponível em: <http://observatoriogeograficoamericalatina.org.mx/egal12/ Geografiasocioeconomica/Geografiaurbana/107.pdf>. Acesso em: 17 fev. 2017.

BEZERRA, M. C. L. Preservação ambiental e planejamento da expansão urbana: o caso do município de Toledo. InterAmerican Development Bank, p. 22, 2013.

BHATTA, B. Analysis of urban growth and sprawl from remote sensing data. Berlim: Heidelberg: Springer Verlag, 2010. 172 p.

BRASIL. Presidência da República. Lei $n^{\circ} 12.651$, de 25 de maio de 2012. Dispõe sobre a proteção da vegetação nativa. Brasília, 2012. Disponível em: <http://www.planalto.gov.br/ccivil_03/_ato2011-2014/2012/lei/l12651.htm >. Acesso em: 18 fev. 2017.

BRUMES, K. R. Cidades: (re)definindo seus papéis ao longo da história. Caminhos de Geografia, v. 2, n. 3, p. 47-56, 2001.

CAMPOS, J. B.; ZOCCHE, J. J.; OOSTERBEEK, L. O uso da terra e as ameaças ao patrimônio arqueológico na região litorânea dos municípios de Araranguá e Içara, extremo sul de Santa Catarina, Brasil. In: LADWIG, N., SCHWALM, H. (Org.). Gestão sócio ambiental das cidades no século XXI: teorias, conflitos e desafios. Florianópolis: Insular, 2013. v. 1. p. 17-30.

COMPANHIA DE PESQUISA DE RECURSOS MINERAIS (CPRM). Mapa geológico do quaternário costeiro do estado do Paraná e Santa Catarina. Rio de Janeiro: CPRM, 1988.

DADRAS, M.; SHAFRI, H. Z. M.; AHMAD, N.; PRADHAN, B.; SAFARPOUR, S. Spatio-temporal analysis of urban growth from remote sensing data in Bandar Abbas city, Iran. The Egyptian Journal of Remote Sensing and Space Science, v. 18, n. 1, p. 35-52, 2015.

DE ANDRADE, L. M. S.; ROMERO, M. A. B. A importância das áreas ambientalmente protegidas nas cidades. In: ENCONTRO NACIONAL DA ASSOCIAÇÃO NACIONAL DE PÓS-GRADUAÇÃO DE PESQUISA EM PLANEJAMENTO URBANO REGIONAL, 11., Salvador, 2005. Anais... 2005. v. 11. Disponível em: <http://unuhospedagem.com.br/revista/rbeur/ index.php/anais/index>. Acesso em: 19 fev. 2017.

EMPRESA BRASILEIRA DE PESQUISAS AGROPECUÁRIAS (EMBRAPA). Sistema Brasileiro de Classificação de Solos. 2. ed. Rio de Janeiro: EMBRAPA-SPI, 2006. 306 p. 
EMPRESA DE PESQUISA AGROPECUÁRIA E DE EXTENSÃO RURAL DE SANTA CATARINA (EPAGRI). Dados e Informações Biofísicas da Unidade de Planejamento Regional Litoral Sul Catarinense (UPR 8). Florianópolis: EPAGRI, 2001. 77 p.

ESTEVAM, D. O.; JORGE, T. P.; SALVARO, G. I. J. Características socioeconômicas da região do extremo sul catarinense: uma análise entre o rural e o urbano. Revista NECAT, v. 3, n. 6, p. 31-56, 2014.

FELIPPE, M. F.; MAGALHÃES JUNIOR, A. P. Consequências da ocupação urbana na dinâmica das nascentes em Belo Horizonte-MG. In: ENCONTRO NACIONAL SOBRE MIGRAÇÕES, 6., 2009. Anais... 2009. p. 1-19.

FLORENZANO, T. G. Imagens de satélite para estudos ambientais. São Paulo: Oficina de Textos, 2002. 97 p.

GROFFMAN, P. M.; CADENASSO, M. L.; CAVENDER-BARES, J.; CHILDERS, D. L.; GRIMM, N. B.; GROVE, J. M.; HOBBIE, S. E.; HUTYRA, L. R.; DARREL JENERETTE, G.; MCPHEARSON, T.; PATAKI, D. E.; PICKETT, S. T. A.; POUYAT, R. V.; ROSIMARSHALL, E.; RUDDELL, B. L. Moving Towards a New Urban Systems Science. Ecosystems, p. 1-6, 2016.

HIGASHI, R. R. Metodologia de uso e ocupação dos solos de cidades costeiras brasileiras através de SIG com base no comportamento geotécnico e ambiental. 486 f. Tese (Doutorado em Engenharia Civil) - Universidade Federal de Santa Catarina, Florianópolis, 2006.

HOBOLD, P. A história de Araranguá: reminiscências desde os primórdios até o ano de 1930. Porto Alegre: Palmarinca, 1994. p. 9-58.

INSTITUTO BRASILEIRO DE GEOGRAFIA E ESTATÍSTICA (IBGE). Censos demográficos. 2017. Disponível em: <http://www. ibge.gov.br/home/mapa_site/mapa_site.php\#populacao>. Acesso em: 22 fev. 2017.

. Manual técnico da vegetação brasileira. 2. ed. Rio de Janeiro: IBGE, 2012. 271 p.

JIANG, B.; YAO, X. Geospatial analysis and modelling of urban structure and dynamics: an overview. In: JIANG, B.; YAO, X. (Eds.). Geospatial analysis and modelling of urban structure and dynamics. New York: Springer, 2010. v. 99. p. 3-11.

KREBS, A. S. J. Contribuição ao conhecimento dos recursos hídricos subterrâneos da área correspondente à bacia Hidrográfica do Rio Araranguá, SC. 375 f. Tese (Doutorado) - Programa de Filosofia e Ciências Humanas, Universidade Federal de Santa Catarina, Florianópolis, 2004.

MARCON, L. Análise da expansão urbana de Araranguá, SC e suas implicações ambientais: uma abordagem interdisciplinar. 92 f. Dissertação (Mestrado em Ciências Ambientais) - Universidade do Extremo Sul Catarinense, Criciúma, 2015.

MOELLER, M. S. Remote sensing for the monitoring of urban growth patterns. International Institute for Sustainability, Arizona State University, Tempe, AZ. 2005. Disponível em: <http://www.isprs.org/proceedings/XXXVI/8-W27/moeller. pdf>. Acesso em: 22 fev. 2017.

MOURA, A. R. D.; NUCCl, J. C. A verticalização como parâmetro na avaliação da qualidade ambiental urbana. In: SIMPÓSIO BRASILEIRO DE GEOGRAFIA FÍSICA APLICADA, 13., Viçosa/MG. Anais... 2009. p. 1-14.

NUCCI, J. C. Qualidade ambiental e adensamento urbano: um estudo de ecologia e planejamento da paisagem aplicado ao distrito de Santa Cecília (MSP). Curitiba: Edição do Autor, 2008. 150 p. Disponível em: <www.Labs.ufpr.br/site/ arquivos/qldade_amb_aden_urbano.pdf>. Acesso em: 20 fev. 2017.

OLIVEIRA, A. M. S.; BRITO, S. N. A. Geologia de Engenharia. São Paulo: Associação Brasileira de Geologia de Engenharia, 1998. p. 488-497.

PEREIMA NETO, J. B. XXI: O século das cidades no Brasil. In: MONTORO, G. C. F.; PASCHOINI, A. P. B.; LEITE, M. A. S.; GUIDOLIN, S. M.; FALCÓN, M. L. O.; MAGALHÃES, W. A.; LASTRES, H. M. M. (Orgs.). Um olhar territorial para o desenvolvimento: Sul. Rio de Janeiro: Banco Nacional de Desenvolvimento Econômico e Social, 2014. p. $270-309$. Disponível em: <https://web.bndes.gov.br/bib.jspui/handle/1408/2941>. Acesso em: 10 fev. 2017. 
PRAMANIK, M. A; STATHAKIS, D. Forecasting urban sprawl in Dhaka city of Bangladesh. Environment and Planning B: Planning and Design, v. 43, n. 4, p. 756-771, 2016.

REIS, N. G. F. Notas sobre urbanização dispersa e novas formas de tecido urbano. São Paulo: Via das Artes, 2006.

SALLES, M. C. T.; GRIGIO, A. M.; SILVA, M. R. F. Expansão urbana e conflito ambiental: uma descrição da problemática do município de Mossoró, RN - Brasil. Sociedade \& Natureza, v. 25, n. 2, p. 281-290, 2013.

SANTA CATARINA. Secretaria de Estado de Coordenação Geral e Planejamento. Atlas escolar de Santa Catarina. Florianópolis: SEPLAN, 1991. 135 p.

SERVIÇO AUTÔNOMO MUNICIPAL DE ÁGUA E ESGOTO (SAMAE). Gestão de qualidade. Açude Valter Belizoni. 2017. Disponível em: <http://site.samaeararangua.com.br/gestao->. Acesso em: 12 fev. 2017.

SHEIBE, L. F. (Org.). Atlas Ambiental da Bacia do Rio Araranguá: Santa Catarina. Florianópolis: UFSC/Cidade Futura, 2010. p. 8-53.

STEWARD, T. A.; PICKETT, S. T. A.; CADENASSO, M. L. How many principles of urban ecology are there? Landscape Ecology, p. 1-7, 11 fev. 2017.

TOMINAGA, L. K.; AMARAL, R. do (Orgs.). Desastres naturais: conhecer para prevenir. São Paulo: Instituto Geológico, 2011. p. 13-97.

WORLD BANK. World development report 1984. New Work: Oxford University Press, 1984.

WU, J.; HE, C.; HUANG, G.; YU, D. Urban landscape ecology: past, present, and future. In: FU, B.; JONES, K. B. (Eds.), Landscape Ecology for Sustainable Environment and Culture. Dordrecht: Springer Netherlands, 2013. 368 p. Disponível em <https://link.springer.com/chapter/10.1007\%2F978-94-007-6530-6_3\#page-1>. Acesso em 25 fev. 2017. 